\title{
Urologic medications and ophthalmologic side effects: a review
}

\author{
Johan Gani, MBBS, FRACS; Nathan Perlis, MD; Sidney B. Radomski, MD, FRCSC
}

Division of Urology, Toronto Western Hospital, University Health Network, Toronto, ON

Cite as: Can Urol Assoc J 2012;6(1):53-8. http://dx.doi.org/10.5489/cuaj.11037

\begin{abstract}
Commonly prescribed urologic medications can have significant ophthalmologic side effects. The existing information can be conflicting. We looked at alpha-blockers and intraoperative floppy iris syndrome (IFIS), phosphodiesterase type 5 (PDE5) inhibitors and non-arteritic ischemic optic neuropathy (NAION) and lastly anticholinergic medications and glaucoma. There is no conclusive scientific data on what to do if the risk of urinary retention is low to moderate, however, we recommend that patients having cataract surgery should stop alpha-blocker medications preoperatively. If there is a high risk of urinary retention, the alpha-blocker should not be withheld, with the active involvement of the ophthalmologist. The role of using 5 alpha-reductase inhibitors (5ARIs) can be considered. There is no convincing evidence that PDE5 inhibitors cause non-arteritic anterior ischemic optic neuropathy (NAION), but patients should be advised of the possible risk of visual loss, especially in patients with risk factors of ischemic heart disease. Acute angle closure glaucoma (AACG or closed angle glaucoma) is very rarely caused by anticholinergic medications in patients with narrow angle anterior eye chambers. However, these medications are safe in patients with open angle glaucoma or treated closed angle glaucoma. Urologists should inquire about the patient's glaucoma history from his/her ophthalmologist before starting an anticholinergic medication.
\end{abstract}

\section{Alpha-blockers and IFIS}

\section{BPH and LUTS}

About 8.7 million American men are potential candidates for treatment of lower urinary tract symptoms (LUTS) due to benign prostatic hypertrophy $(\mathrm{BPH})$ yearly. ${ }^{1}$ Medical therapy for $\mathrm{BPH} / \mathrm{LUTS}$ is considered the first-line treatment modal- ity. Tamsulosin is an alpha $1 \mathrm{~A}$ adrenergic receptor blocker and works in LUTS due to $\mathrm{BPH}$ by relaxing the bladder neck and smooth muscle of the prostate gland. Alfuzosin, terazosin and doxazosin are also alpha-blockers, but not as specific as tamsulosin. All four drugs are equally effective in treating LUTS. The advantage of a very specific alphablocker is that there is the potential of fewer side effects. In the case of alfuzosin and tamsulosin, there is no hypotension that generally occurs with these drugs as opposed to the less selective alpha-blockers (terazosin and doxazosin). Tamsulosin is now the most commonly used medication for LUTS due to BPH; it has minimal side effects (dizziness 5\% and abnormal ejaculation $6 \%$ ).

LUTS is very common in men as they age. It has been found that $46 \%$ of men aged 70 to 79 years have moderate to severe LUTS. ${ }^{2}$ Also common is cataract surgery; it is one of the most common operations performed in elderly men and women in North America. Each year, 5.3\% of elderly American residents undergo cataract surgery. ${ }^{3}$ Therefore, it is expected that a significant number of men undergoing cataract surgery may be on alpha-blockers for LUTS.

\section{IFIS}

Intraoperative floppy iris syndrome (IFIS) is a complication that may occur during cataract surgery. Adequate pupil dilation and normal iris function are required to ensure a safe surgery. Tamsulosin and other alpha-blockers may impede pupil dilation and cause the "IFIS triad" (a flaccid and billowing iris, iris prolapse through the surgical incisions and progressive intraoperative pupil constriction). ${ }^{4}$ This triad can potentially result in complications, such as iris trauma and posterior capsule rupture.

Chang and Campbell were the first to report on IFIS. ${ }^{4}$ They stated that IFIS occurred only in patients taking tamsulosin and that almost all patients who developed IFIS were on tamsulosin. Since the release of their report, these find- 
ings have been found to be incorrect. The reported incidence of IFIS in the general population is $0.6 \%$ to $3.7 \%$. Furthermore, IFIS developed in $40 \%$ to $100 \%$ of patients exposed to tamsulosin and $0 \%$ to $66.7 \%$ of patients exposed to other alpha-blockers. ${ }^{5-14}$ In a retrospective review of 1612 cataract surgeries performed in 1298 patients, Srinivasan and colleagues found that 65 patients $(5 \%)$ were on an alphablocker for LUTS/BPH. IFIS occurred in $14.7 \%$ of these 65 patients (14/95 surgeries). ${ }^{15}$ In those who developed IFIS, most of them were on tamsulosin, but IFIS also occurred in smaller numbers in patients on terazosin and doxazosin. Furthermore, although the numbers were small, there was no correlation between the dose of the alpha-blocker and IFIS. Subsequent reports, similar to our own, have shown that terazosin, doxazosin and alfuzosin can be related to IFIS. ${ }^{16,17}$ It is likely that the entire class of alpha-blockers can cause IFIS. However, the syndrome seems to be less common and less severe with others as compared to when tamsulosin is used.

\section{Is the effect of alpha-blockers on the iris permanent?}

There is evidence to suggest that IFIS can occur up to several years after stopping tamsulosin., 4, Prata and colleagues demonstrated that iris muscle atrophy may occur and that tamsulosin may cause a permanent effect in the iris. ${ }^{18}$ However, no definitive study has been done to confirm permanent muscle atrophy of the iris. Furthermore, this type of permanent effect is not seen with the smooth muscle of the bladder neck and prostatic urethra.

Another concern is whether the duration of the alphablocker affects the development of IFIS. Chang and colleagues reported that IFIS can occur 2 weeks after starting tamsulosin. ${ }^{6}$ Shah and colleagues, however, reported that it occurred after only 2 days of tamsulosin intake. ${ }^{19}$ Furthermore, detectable amounts of tamsulosin have been found in the aqueous humour even 28 days after tamsulosin was stopped..$^{20}$ In their study, Chang and colleagues stopped tamsulosin 1 to 8 weeks prior to surgery and found that the severity of IFIS was unchanged, but the preoperative pupil size was larger in patients who stopped tamsulosin. ${ }^{6}$ Therefore, the actual minimum duration of exposure to an alpha-blocker required to cause IFIS is unknown and may be dependent on the alpha-blocker.

If there is a possible permanent effect on the iris with alpha-blockers, then patients taking them and who are also having bilateral cataract surgery, should get bilateral IFIS. However, some authors, including ourselves, have shown that having IFIS in one eye does not necessarily result in IFIS in the second eye. ${ }^{11,15,16}$

Bell and colleagues assessed the risk of adverse events following cataract surgery. They found that exposure to tamsulosin within 14 days of surgery was significantly associated with serious postoperative ophthalmologic adverse events. ${ }^{5}$ Interestingly, they also found that patients who had previous exposure to tamsulosin were not at increased risk and there was no increased risk with other alpha-blockers just before surgery. This evidence would suggest that a permanent effect of tamsulosin or any other alpha-blockers on the iris was unlikely.

\section{Other drugs and IFIS}

There are other conditions or drugs that have been associated with IFIS. Mianserin (antidepressant), zuclopenthixol (antipsychotic), labetalol (antihypertensive) and saw palmetto have alpha-blocking activity and have been related to IFIS. ${ }^{21-24}$ IFIS, associated with finasteride, has been reported in two patients. ${ }^{25}$ The exact mechanism by which finasteride is linked with IFIS is unclear and may be coincidental. Male gender, hypertension and endothelial dysregulation may affect the iris and may be associated with IFIS. ${ }^{10,15,26}$

\section{Risk of urinary retention}

Atropine and atropine-like drugs are commonly used during cataract surgery. There is concern that stopping an alphablocker and using an anticholinergic drug during cataract surgery may precipitate urinary retention. Most men on alpha-blockers take them for LUTS due to BPH and do not have retention. The chances of precipitating retention due to stopping an alpha-blocker are low even when an anticholinergic is used. ${ }^{27,28}$ Furthermore, anticholinergics have been used increasingly with and without alpha-blockers to treat LUTS, with very low rates of retention. ${ }^{28}$

\section{Should alpha-blockers be stopped prior to cataract surgery?}

There is no reliable preoperative method to predict whether IFIS will occur and how severe it will be. Recommendations have been put forth in regards to alpha-blocker use in men who need cataract surgery. If a patient is scheduled to have cataract surgery and is not on an alpha-blocker, then he should not go on an alpha-blocker until after the cataract surgery is completed. There is controversy about if and when an alpha-blocker should be stopped prior to cataract surgery.

The benefit of stopping alpha-1 blocker therapy prior to cataract surgery has not been established..$^{29}$ There is little evidence to suggest that stopping an alpha-blocker preoperatively prevents IFIS. Similarly, there is weak evidence to suggest that IFIS can also occur many months after stopping an alpha-blocker. ${ }^{4,6,30,31}$ Recommendations have varied from stopping tamsulosin 1 to 4 weeks before cataract surgery to not stopping the drug at all. 6,32,33 These varying recommendations seem to be based on surgical specialty; urologists prefer stopping alpha-blockers and ophthalmologists prefer not 
stopping the drug. In the tamsulosin product monogram alert in 2005, the Food and Drug Administration (FDA) warned that the patient's ophthalmologist should be prepared for possible modifications to their surgical technique. Lastly, there is no evidence that alpha-blockers cannot be safely resumed shortly after cataract surgery.

\section{Potential role for 5 alpha-reductase inhibitors}

The addition of a 5 alpha-reductase inhibitor (5ARI), such as finasteride, to the alpha-blocker can improve a patient's LUTS. Once the 5ARI has established its efficacy after a period of combination therapy, the alpha-blocker may be stopped before cataract surgery without concern of precipitating urinary retention at the time of surgery. ${ }^{34,35}$

\section{Women and alpha-blockers}

An increasing number of women are being placed on alphablockers for hypertension, renal colic and voiding dysfunction. Therefore, the potential for IFIS in women should be considered.

\section{Recommendations}

Urologists and family physicians should ask about the potential for cataract surgery in any man or woman who may require an alpha-blocker. If cataract surgery is being considered, it is recommended to hold off on an alpha-blocker until after the surgery. If a patient is on an alpha-blocker, the ophthalmologist should be informed.

The more difficult question is what should be done if a patient is already on an alpha-blocker. We feel that if a patient has mild to moderate LUTS and has not been in retention, the risk of retention is low and his alpha-blocker should be stopped at least 2 weeks (possibly up to 4 weeks) before cataract surgery. This will potentially minimize the risk of IFIS. Switching to another alpha-blocker is of no value. If the patient has severe LUTS and has been in retention in the past and is at risk of it re-occurring (i.e., large postvoid residuals), it is prudent to continue the alphablockers. The patient's ophthalmologist should be involved in this decision.

It is not practical to have every patient who has LUTS who is being considered for alpha-blocker therapy to be seen by an ophthalmologist before starting an alpha-blocker. Lastly, consideration should be made for the use of 5ARIs when men with LUTS due to BPH are being considered for cataract surgery with or without alpha-blockers.

\section{PDE5 inhibitors and NAION}

\section{What is NAION?}

Anterior ischemic optic neuropathy (AION) is divided into two types: arteritic AION (or AAION) and non-arteritic AION (NAION). AAION is caused by temporal arteritis and occurs more commonly in the elderly. NAION occurs in patients with cardiovascular risk factors and "crowded" optic discs. NAION is more common in younger patients. It is the most common cause of acute optic neuropathy in adults (1500 to 6000 annually in United States). ${ }^{36}$ NAION can be simply described as an optic nerve "stroke" or "compartment syndrome" of the optic nerve.

NAION is characterized by acute unilateral loss of vision, usually upon awakening. The vision in one eye becomes obscured by a dark shadow, often involving just the upper or lower half of the visual field, usually medially towards the nose. In 6 months, $42.7 \%$ of patients improve and $12.4 \%$ of patients become worse. In 5 years, the other eye becomes involved in about $15 \%$ of patients. ${ }^{37}$ Most cases were only mild to moderate and involved only one hemisphere. Patients rarely become totally blind.

There are two risk factors for developing NAION. Firstly, patients with cardiovascular risk factors, like hypertension, hyperlipidemia, diabetes and ischemic heart disease, are at increased risk. The second factor is the "crowded" optic disc. In the eye, axons from the retinal ganglion cells collect into the optic nerve at the optic disc. The optic nerve passes through the wall of the eye (cup) to carry the visual signals from the eye to the brain. In a normal eye, the cup is usually $20 \%$ to $30 \%$ larger than the nerve diameter. Patients with a low cup-to-disc ratio (a crowded optic disc) have a higher risk of developing $\mathrm{NAION}$.

The postulated mechanism for NAION is that during sleep, a lower blood pressure causes arterial hypoperfusion to parts of the optic disc. This in turn swells the optic disc, and in a tight cup, causes more ischemia, resulting in areas of retinal infarction.

There are no clinically effective treatments for NAION. Preventive measures for the other eye are also ineffective. A large, non-randomized controlled study reported that oral steroids may help if given within 2 weeks of onset. Visual acuity and visual fields showed improvement and can continue to improve for up to 6 months. ${ }^{38}$ Evidence is lacking on the use of antithrombotics (e.g., acetylsalicylic acid), and neuroprotectives (e.g., brimonidine, estrogen). Case reports of intravitreal steroid injection ${ }^{39,40}$ or anti-vascular endothelial growth factor (anti-VEGF) agents have been published. Surgical decompression has also been described as ineffective. ${ }^{41}$ 
Gani et al.

\section{Is NAION associated with PDE5 inhibitor use?}

There is no evidence that PDE5 inhibitors increase the risk of NAION. Only a few case reports and small series about NAION and PDE5 inhibitor use have been reported. McGwin and colleagues reported on 76 patients in a case control study and found a statistically significant difference with PDE5 inhibitor use only in those patients with previous acute myocardial infarcts. ${ }^{42}$ A study in the United Kingdom reported only one case of NAION in 16129 patients using tadalafil. ${ }^{43} \mathrm{~A}$ post-marketing safety database of sildenafil reported no NAION cases in 39277 patients. ${ }^{44}$ Gorkin and colleagues found that the incidence of NAION in sildenafil users (2.8 per 100000 patient-years of sildenafil exposure) was similar to the incidence of NAION in the general American population in men aged $>50$ years $(2.52$ per 100 000). ${ }^{45}$ Bella and colleagues found less than 50 American cases reported by the FDA and less than 5 cases in Canada until 2007. ${ }^{46}$

A causal relationship between NAION and PDE5 inhibitor use is difficult to show because the risk factors for erectile dysfunction and NAION are similar. NAION is thought to be due to arteriolar constriction in the optic nerve. However, PDE5 inhibitors cause vasodilation, not vasoconstriction. There have only been a few cases reported considering many men safely using PDE5 inhibitors. The FDA, however, has labelled it as "possibly causal."

\section{Other visual side effects of PDE5 inhibitors}

Sildenafil, at high doses, can cause mild and transient changes in colour discrimination, especially within the blue-green spectrum. This is thought to be due to the cross inhibition of PDE6, which is located in the rod and cone photoreceptors. Patients describe a blue tinge to their vision and increased brightness of lights, but not blindness. Vardenafil has less selectivity for PDE6 and tadalafil has the least selectivity when compared to sildenafil. Therefore visual abnormalities with vardenafil and tadalafil are more uncommon.

\section{Recommendations}

Urologists should counsel patients on the risk of visual loss before starting PDE5 inhibitors, especially in patients with risk factors of ischemic heart disease. If the patient has preexisting NAION in one eye, PDE5 inhibitors should not be prescribed. If symptoms occur, patients should stop using PDE5 inhibitors and seek help.

\section{Anticholinergic therapy and glaucoma}

Oral anticholinergic therapy is the mainstay treatment for overactive bladder $(\mathrm{OAB})$ and urinary urge incontinence
(UUI). This class of medication works by inhibiting muscarinic receptors, specifically $\mathrm{M} 3$, located on detrusor smooth muscle fibres in the urinary bladder. Other muscarinic receptors in salivary glands, bowel and eyes are also blocked causing dry mouth (20\% to $40 \%$ ), constipation (10\% to $20 \%$ ) and blurry vision ( $1 \%$ to $2 \%$ ). These effects are reversible with discontinuation of the offending agent. ${ }^{47}$

There is concern that anticholinergic agents used for $\mathrm{OAB}$ and UUI can cause acute angle closure glaucoma (AACG) because medication-induced AACG has been welldescribed with other drugs, such as ipratropium bromide and atropine that have anticholinergic activity. ${ }^{48}$ To date, however, there has only been one case reported by Sung and colleagues of AACG in an 80-year-old woman taking oxybutynin $2.5 \mathrm{mg}$ twice daily. Her unilateral intraocular pressure was $56 \mathrm{mmHg}$ and she was managed with laser iridotomy, which corrected her vision and pressure by two weeks postoperatively. ${ }^{49}$

In a normal resting state, aqueous humour produced by the ciliary body flows between the lens and iris and is drained by the trabecular meshwork in the corner of the anterior chamber of the eye. In patients with an anatomically narrow-angled anterior chamber, constriction of the iris and subsequent dilatation of the pupil can narrow the anterior chamber even further. Anticholinergic agents can produce a mydriatic effect, and this pupillary dilatation in an already narrowed anterior chamber can block the flow of aqueous humour into the trabecular meshwork altogether. Fluid then accumulates and results in an acute rise in intraocular pressure, ischemia of the optic nerve and blindness. Treatment for AACG involves immediate laser iridotomy to provide a channel for aqueous humour drainage and reduce intraocular pressure. If diagnosed and treated quickly, visual loss is reversible. ${ }^{50}$

Although the true incidence and risk of AACG in patients taking anticholinergic medication is unknown, it is very rare. Narrow angle glaucoma has been a contraindication for entry into all major urologic anticholinergic trials, including the OBJECT (Overactive Bladder: Judging Effective Control and Treatment), OPERA (Overactive Bladder: Performance of Extended Release Agents) and ACET (Antimuscarinic Clinical Effectiveness Trial) trials. None have reported AACG as an adverse event. ${ }^{51-53}$ Anticholinergics do not seem to raise intraocular pressure in patients without glaucoma. In a small single-blind prospective randomized trial, there was no change in intraocular pressure from baseline in patients taking either $2 \mathrm{mg}$ of tolterodine twice a day or $5 \mathrm{mg}$ oxybutynin three times a day. ${ }^{54}$

A group from Japan outlined their practices in a review of 367 patients initiated on anticholinergics for OAB. All patients were asked about a glaucoma history and, if positive, were referred to an ophthalmologist to clarify the type of glaucoma. Patients with either open angle glaucoma or 
treated closed angle glaucoma were offered anticholinergic agents. Therapy was not given to two patients with closed angle glaucoma who refused iridotomy. There was no incident of increased intraocular pressure or AACG in any of the patients, including those with open angle glaucoma and treated closed angle glaucoma. ${ }^{55}$

\section{Recommendations}

AACG is a very rare complication that can occur in patients taking anticholinergic medication for $\mathrm{OAB}$ and $\mathrm{UUI}$ that have narrow anterior chambers of their eyes. There has only been one case report of oxybutynin causing AACG, and no other agent has been implicated. Urologists should inquire about their patient's glaucoma history when prescribing anticholinergics. These drugs are safe to prescribe to patients with open angle or treated closed angle glaucoma. Ophthalmologic referral should be sought if the patient's glaucoma type cannot be characterized. With the physiologic data supporting the safety of these drugs for patients with open angle or treated closed angle glaucoma, these patients may be eligible for entry into future anticholinergic trials.

Competing interests: Dr. Radomski is on the advisory boards for Pfizer, Astellas, Lilly and Allergan.

This paper has been peer-reviewed.

\section{References}

1. Jacobsen SJ, Girman CJ, Guess HA, et al. New Diagnostic and treatment guidelines for benign prostatic hyperplasia. Arch Intern Med 1995;155:477-81. http://dx.doi.org/10.1001/ archinte. 1995.00430050053006

2. Chute $(G$, Panser $L A$, Girman $C \mathrm{CJ}$, et al. The prevalence of prostatism: a population based survey of urinary tract symptoms. J Urol 1993;150:85-9.

3. Williams A, Sloan FA, Lee PP. Longitudinal rates of cataract surgery. Arch Ophthalmol 2006;124:1308-14. http://dx.doi.org/10.1001/archopht.124.9.1308

4. Chang DF, Campbell JR. Intraoperative floppy iris syndrome associated with tamsulosin. J Cataract Refract Surg 2005;31:664-73. http://dx.doi.org/10.1016/i.jcrs.2005.02.027

5. Bell $C M$, Hatch WV, Fischer WV, et al. Association between tamsulosin and serious ophthalmic adverse events in older men following cataract surgery. JAMA 2009;301:1991-6. http://dx.doi.org/10.1001/ jama.2009.683

6. Chang DF, Osher RH, Wang L, et al. A prospective multicenter evaluation of cataract surgery in patients taking tamsulosin (Flomax). Ophthalmology 2007;114:957-64. http://dx.doi.org/10.1016/i.ophtha.2007.01.011

7. Chadha V, Borooah S, Tey A, et al. Floppy lris behavior during cataract surgery: associations and variations. Br J Ophthalmol 2007;91:40-2. http://dx.doi.org/10.1136/bj0.2006.103036

8. Blouin MC, Blouin J, Perreault $S$, et al. Intraoperative floppy-iris syndrome associated with alpha 1-adrenoceptors comparison of tamsulosin and alfuzosin. J Cataract Refract Surg 2007;33:1227-34. http:// dx.doi.org/10.1016/i.jurs.2007.03.032

9. Keklikci U, Isen K, Unlu K, et al. Incidence, clinical findings and management of intraoperative floppy iris syndrome associated with tamsulosin. Acta Ophthalmol 2009;87:306-9. http://dx.doi.org/10.1111/ j.1755-3768.2008.01246.x

10. Altan-Yaycioglu R, Gedik S, Pelit A, et al. Clinical factors associated with floppy iris signs: a prospective study from two centers. Ophthalmic Surg Lasers Imaging 2009;40:232-8. http://dx.doi. org/10.3928/15428877-20090430-02
11. Takmaz T, Can I. Clinical features, complications and incidence of floppy iris syndrome in patients taking tamsulosin. Eur J Ophthalmol 2007;17:909-13.

12. Oshika $T$, Ohashi $Y$, Inamura $M$, et al. Incidence of intraoperative floppy iris syndrome in patients on either systemic or topical alphal-adrenoceptor antagonists. Am J Ophthalmol 2007;143:150-1. http:// dx.doi.org/10.1016/i.ajo.2006.07.046

13. Neff KD, Sandoval HP, de Castro LEF, et al. Factors associated with intraoperative floppy iris syndrome. Ophthalmology 2009;116:658-63. http://dx.doi.org/10.1016/i.ophtha.2008.12.026

14. Cheung CM, Awan MA, Peh KK, et al. Comment on: incidence of intraoperative floppy iris syndrome in patients on either systemic or topical alpha 1 adrenoceptor antagonists. Am J Ophthalmol 2007;143:10701. http://dx.doi.org/10.1016/i.ajo.2007.02.044

15. Srinivasan $S$, Radomski $S$, Chung J, et al. Intraoperative floppy iris syndrome during cataract surgery in men using alpha blockers for benign prostatic hypertrophy. J Cataract Refract Surg 2007;33:1826-7. httr://dx.doi.org/10.1016/i.jors.2007.06.033

16. Issa $\mathrm{SA}$, Hadid $\mathrm{OH}$, Baylis 0 , et al. Alpha antagonists and intraoperative floppy iris syndrome: A Spectrum. Clin Ophthalmol 2008;2:735-41. http://dx.doi.org/10.2147/0PTH.S2697

17. Cantrell MA, Bream-Rouwenhorst HR, Steffensmeier A, et al. Intraoperative floppy iris syndrome associated with alpha 1-adrenergic receptor antagonists. Ann Pharmacother 2008;42:558-63. http://dx.doi. org/10.1345/aph. 1 K679

18. Prata TS, Palmiero PM, Angelilli A, et al. Iris morphologic changes related to alpha one adrenergic receptor antagonists: implications for floppy iris syndrome. Ophthalmology 2009;116:877-81. http://dx.doi. org/10.1016/i.ophtha.2008.12.040

19. Shah N, Tendulkar M, Brown R. Should we anticipate intraoperative floppy iris syndrome (IFIS) even with very short history of tamsulosin? Eye 2009;23:740. http://dx.doi.org/10.1038/eye.2008.95

20. Chang DF, Braga-Mele R, Mamalis N, et al. ASCRS white paper: clinical review of intraoperative floppy-iris syndrome. J Cataract Refract Surg 2008;34:2153-62. http://dx.doi.org/10.1016/i.jcrs.2008.08.031

21. Ugarte M, Leong T, Russam S, et al. Intraoperative floppy-iris syndrome, alphal-adrenergic antagonists, and chronic intake of mianserin: is there an association? I Cataract Refract Surg 2007;33:170-1. http:// dx.doi.org/10.1016/i.jors.2006.07.047

22. Pringle E, Packard R. Antipsychotic agents as an etiologic agent of IFIS. J Cataract Refract Surg 2005;31:2240-1. http://dx.doi.org/10.1016/i.jcrs.2005.12.066

23. Calotti F, Steen D. Labetalol causing introperative floppy iris syndrome. J Cataract Refract Surg 2007;33:170. http://dx.doi.org/10.1016/i.jcrs.2006.07.048

24. Yeu E, Grostern R. Saw palmetto and intraoperative floppy-iris syndrome. J Cataract Refract Surg 2007;33:927-8. http://dx.doi.org/10.1016/i.jcrs.2006.12.032

25. Issa SA, Dagres E. Intraoperative floppy-iris syndrome and finastride intake. J Cataract Refract Surg 2007;33:2142-3. http://dx.doi.org/10.1016/i.jcrs.2007.07.025

26. Schwinn DA, Afshari NA. Alpha 1 - Adrenergic receptor antagonists and the iris: new mechanistic insights into floppy iris syndrome. Surv Ophtlmol 2006;51:501-12. http://dx.doi.org/10.1016/i. survophthal.2006.06.011

27. Abrams P, Kaplan S, De HJ, et al. Safety and tolerability of tolterodine for the treatment of overactive bladder in men with bladder outlet obstruction. J Urol 2006;175:999-1004. http://dx.doi.org/10.1016/ S0022-5347 (05)00483-0

28. Kaplan $S A$, Roehrborn $C G$, Rovner ES, et al. Tolterodine and tamsulosin for treatment of men with lower urinary tract symptoms and overactive bladder: a randomized controlled trial. JAMA 2006;296:2319-28. http://dx.doi.org/10.1001/jama.296.19.2319

29. U.S. Food and Drug Administration. Safety Alert: Flomax (tamsulosin) HCL. 2005. www.fda.gov/safety (Accessed February 1, 2012).

30. Nguyen DQ, Sebastian RT, Kyle G. Surgeon's experiences of the intraoperative floppy iris syndrome in the United Kingdom. Eye 2007;21:443-4. http://dx.doi.org/10.1038/sj.eye.6702616

31. Osher RH. Association between IFIS and flomax. I Cataract Refract Surg 2006;32:547. http://dx.doi. org/10.1016/i.jurs.2006.01.008

32. Lawrentschuk N, Bylsma GW. Intraoperative "floppy iris" syndrome and its relationship to tamsulosin: a urologists guide. BJU Int 2006;97:2-4. http://dx.doi.org/10.1111/j.1464-410X.2006.05960.x

33. Nguyen DQ, Sebastian RT, Philip J. Intraoperative floppy iris syndrome associated with tamsulosin. BJU Int 2006;97:197. http://dx.doi.org/10.1111/j.1464-410X.2006.06049_1.x

34. Issa MM, Lin PJ, Eaddy MT, et al. Comparative analysis of alpha-blocker utilization in combination with 5-alpha reductase inhibitors for enlarged prostate in a managed care setting among Medicare-aged men. Am J Manag Care 2008;14(5 Suppl2):S160-6.

35. Barkin J, Guimaraes $M$, Jacobi $G$, et al. Alpha-blocker therapy can be withdrawn in the majority of men following initial combination therapy with the dual 5 alpha-reductase inhibitor dutasteride. Eur Urol 2003;44:461-6. http://dx.doi.org/10.1016/S0302-2838(03)00367-1

36. Hattenhaver MG, Leavitt JA, Hodge DO, et al. Incidence of nonarteritic anterior ischemic optic neuropathy. Am J Ophthalmol 1997;123:103-7. 
Gani et al.

37. Newman NJ, Scherer R, Langenberg P, et al. Ischemic Optic Neuropathy Decompression Trial Research Group. The fellow eye in NAION: report from the ischemic optic neuropathy decompression trial follow-up study. Am J Ophthalmol 2002;134:317-28. http://dx.doi.org/10.1016/S0002-9394(02)01639-2

38. Hayreh SS, Zimmerman MB. Non-arteritic anterior ischemic optic neuropathy: role of systemic corticosteroid therapy. Graefes Arch Clin Exp Ophthalmol 2008;246:1029-46. Epub 2008 Apr 11.

39. Sohn BJ, Chun BY, Kwon JY. The effect of an intravitreal triamcinolone acetonide injection for acute nonarteritic anterior ischemic optic neuropathy. Korean J Ophthalmol 2009;23:59-61. http://dx.doi. org/10.3341/kjo.2009.23.1.59

40. Yaman $A$, Selver $O B$, Saatci $A 0$, et al. Intravitreal triamcinolone acetonide injection for acute non-arteritic anterior ischemic optic neuropathy. Clin Exp Optom 2008;91:561-4. http://dx.doi.org/10.1111/ j.1444-0938.2008.00287.x

41. The Ischemic Optic Neuropathy Decompression Trial Research Group. Optic nerve decompression surgery for nonarteritic anterior ischemic optic neuropathy (NAION) is not effective and may be harmful. JAMA 1995;273:625-32. http://dx.doi.org/10.1001/jama.1995.03520320035038

42. McGwin GJ, Vaphiades M, Hall T, et al. Non-arteritic anterior ischemic optic neuropathy and the treatment of erectile dysfunction. Br J Ophthalmol 2006;90:154-7. http://dx.doi.org/10.1136/bjo.2005.083519

43. Hazell L, Cornelius V, Wilton LV, et al. The safety profile of tadalafil as prescribed in general practice in England: results from a prescription-event monitoring study involving 16129 patients. BJU Int 2009;103:506-14. http://dx.doi.org/10.1111/j.1464-410X.2008.08000.x

44. Giuliano F, Jackson G, Montorsi $F$, et al. Safety of sildenafil citrate: review of 67 double-blind placebocontrolled trials and the post-marketing safety database. Int I Clin Pract 2010;64:240-55. http://dx.doi. org/10.1111/i.1742-1241.2009.02254.x

45. Gorkin L, Hvidsten K, Sobel RE, et al. Sildenafil citrate use and the incidence of nonarteritic anterior ischemic optic neuropathy. Int I Clin Pract 2006;60:500-3. http://dx.doi.org/10.1111/j.13685031.2006.00904.x

46. Bella AJ, Brant WO, Lue TF, et al. Non-arteritic anterior ischemic optic neuropathy (NAION) and phosphodiesterase type-5 inhibitors. Can J Urol 2006;13:3233-8.
47. Andersson K, Wein A. Pharmacologic Management of Storage and Emptying Failure. Campbell-Walsh Urology. Alan J. Wein, editor. Philadelphia: PA: Saunders Elsevier, 2007;2091-123.

48. Lachkar Y, Bouassida W. Drug-Induced Acute Angle Closure Glaucoma. Curr Opin Ophthalmol 2007;18:12933. http://dx.doi.org/10.1097//CU.0b013e32808738d5

49. Sung V, Corridan P. Acute-Angle Closure Glaucoma as a Side-Effect of Oxybutynin. Br J Urol 1998;81:6345. http://dx.doi.org/10.1046/j.1464-410x.1998.00403.x

50. Subank-Sharpe I, Low S, Nolan W, et al. Pharmacological and Environmental Factors in Primary AngleClosure Glaucoma. Br Med Bull 2010; 93:125-43. http://dx.doi.org/10.1093/bmb//dp042

51. Appell R, Sand P, Dmochowski R, et al. Prospective Randomized Controlled Trial of Extended-Release Oxybutynin Chloride and Tolterodine Tartrate in the Treatment of Overactive Bladder: Results of the OBJECT Study. Mayo Clin Proc 2001;76:358-63.

52. Diokno A, Appell RA, Sand PK, et al. Prospective, Randomized, Double-Blind Study of the Efficacy and Tolerability of the Extended-Release Formulations of Oxybutynin and Tolterodine for Overactive Bladder: Results of the OPERA Trial. Mayo Clin Proc 2003;78:687-95. http://dx.doi.org/10.4065/78.6.687

53. Sussman D, Garely A. Treatment of Overactive Bladder with Once-daily Extended-release Tolterodine or Oxybutynin: The Antimuscarinic Clinical Effectiveness Trial (ACET). Curr Med Res Opin 2002;18:177-84. http://dx.doi.org/10.1185/030079902125000570

54. Altan-Yaycioglu R, Yaycioglu 0, Aydin Akova Y, et al. Ocular Side-Effects of Tolterodine and Oxybutynin, a Single-Blind Prospective Randomized Trial. Br J Clin Pharmacol 2005;59:588-92. http://dx.doi. org/10.1111/i.1365-2125.2005.02356.x

55. Kato K, Yoshida K, Suzuki K, et al. Managing Patients with an Overactive Bladder and Glaucoma: A Questionnaire Survey of Japanese Urologists on the Use of Anticholinergics. BJU Int 2005;95:98-101. http://dx.doi.org/10.1111/j.1464-410X.2004.05259.x

Correspondence: Dr. Sidney B. Radomski, Division of Urology, Toronto Western Hospital, University Health Network, 399 Bathurst St., MP8-304, Toronto, 0N M5T 2S8; radomski99@rogers.com 